\title{
A Case for Enantioselective Allylic Alkylation Catalysed by Palladium Nanoparticles
}

\author{
Susanna Jansat, ${ }^{a, b}$ Montserrat Gómez, ${ }^{a}$ * Karine Philippot, ${ }^{b *}$ Guillermo Muller, ${ }^{a}$ Ester \\ Guiu, ${ }^{c}$ Carmen Claver, ${ }^{c}$ Sergio Castillón, ${ }^{c}$ and Bruno Chaudret ${ }^{b *}$ \\ a) Departament de Química Inorgànica, Universitat de Barcelona, Martí i Franquès 1-11, 08028 \\ Barcelona, Spain, b) Laboratoire de Chimie de Coordination, CNRS, 205, route de Narbonne, \\ 31077 Toulouse Cédex 04, France c) Departament de Química Física i Química Inorgànica, $i$ \\ Química Analítica i Química Orgànica, Universitat Rovira i Virgili, Pl. Imperial Tarraco, 143005 \\ Tarragona, Spain
}

manuscript ja036132k

\section{Supplementary material}




\section{A. Pd NANOPARTICLES SYNTHESIS AND CHARACTERIZATION}

\section{A1. Synthesis of palladium nanoparticles $\left(\right.$ Coll.1, 2 and 3) from $\mathbf{P d}_{2}\left(\mathrm{dba}_{3}\right.$}

$40 \mathrm{mg}$ of $\mathrm{Pd}_{2}(\mathrm{dba})_{3}(0.043 \mathrm{mmol})$ were dissolved under argon at $-10^{\circ} \mathrm{C}$ in a solution of $40 \mathrm{~mL}$ of THF containing $0.017 \mathrm{mmol}$ of the ligand (diphosphite 1: $18.6 \mathrm{mg}$; xylose 3: $3.3 \mathrm{mg}$; biphenol $2: 7.2 \mathrm{mg}$ ) in a closed pressure bottle. After pressurization at room temperature under 3 bars for 30 minutes, the initial red solution became grey in a few minutes (approximately 20). The vigorous magnetic stirring and the pressure of $\mathrm{H}_{2}$ were maintained for 18 hours. After that period of time, the hydrogen pressure was eliminated, and a drop of the colloidal solution was deposited under argon on a holey carbon covered copper grid for microscopy analysis. Evaporation of the solvent gave a black precipitate which was washed with pentane $(3 \times 10 \mathrm{~mL})$ and dried at low pressure. The colloids were characterized by TEM analysis, elemental analysis, IR and WAXS.

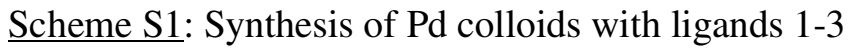

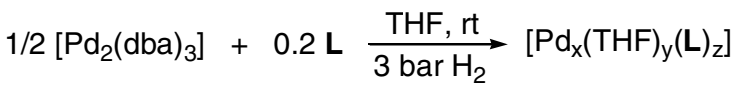

$$
\begin{aligned}
& \text { - dba Coll.1 }(L=1) \\
& \text { Coll.2 }(L=2)
\end{aligned}
$$

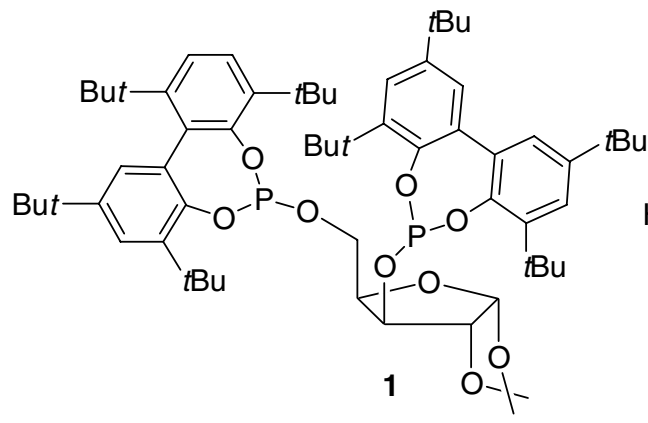<smiles>CC(C)(C)c1cc(Br)c(O)c(-c2cc(C(C)(C)C)cc(C(C)(C)C)c2O)c1</smiles> 


\section{A2. Characterization of Coll.1}

Figure S1: WAXS analysis: comparison of the rdf of Coll.1 with a theoretical rdf calculated for $4 \mathrm{~nm}$ fcc Pd nanoparticles

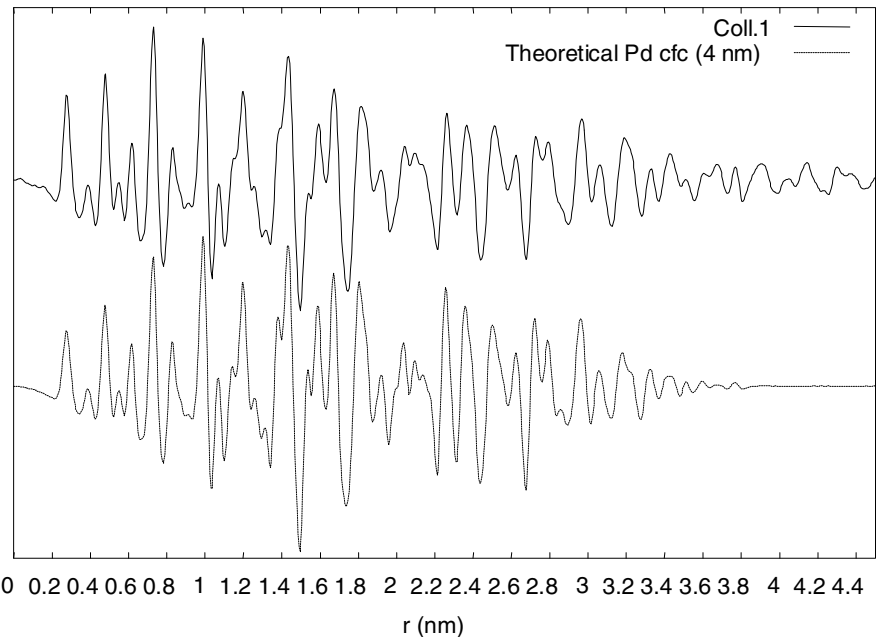

Figure S2: TEM micrograph of the crude nanoparticles solution after synthesis and size histogram built from ca. 360 nanoparticles
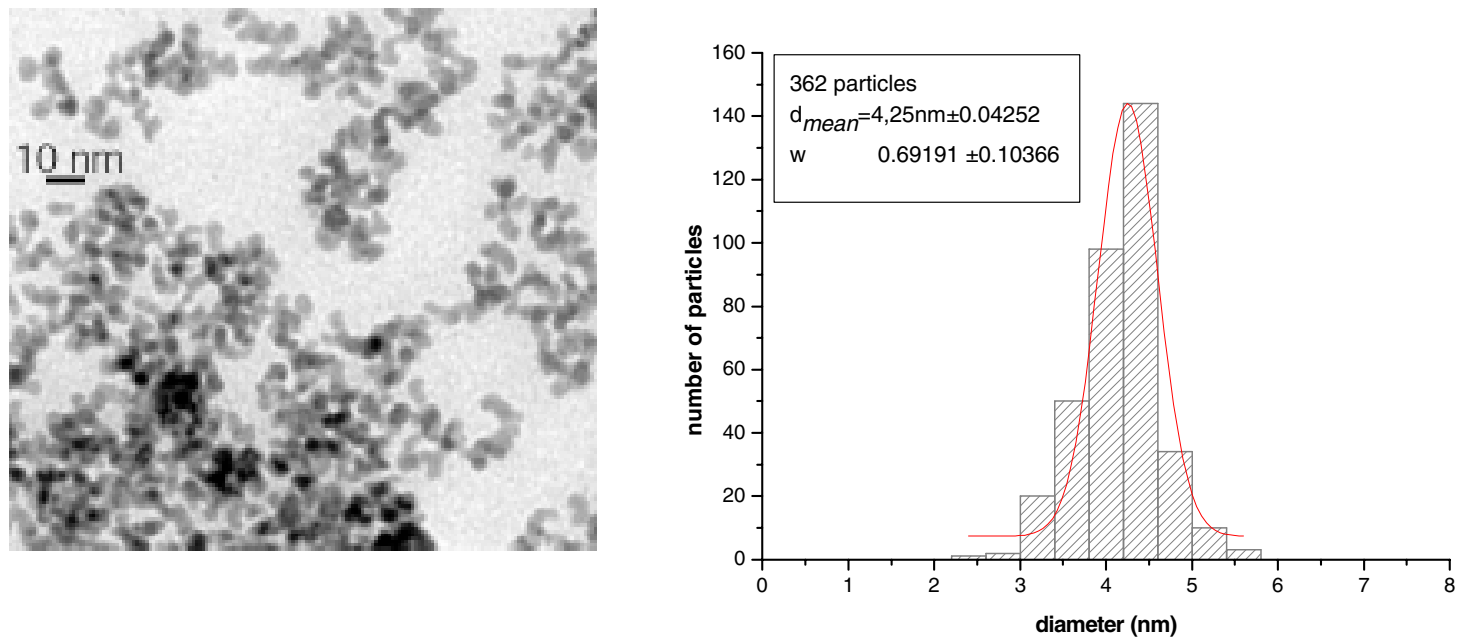
Figure S3: TEM micrographs of Coll.1 before and after catalysis

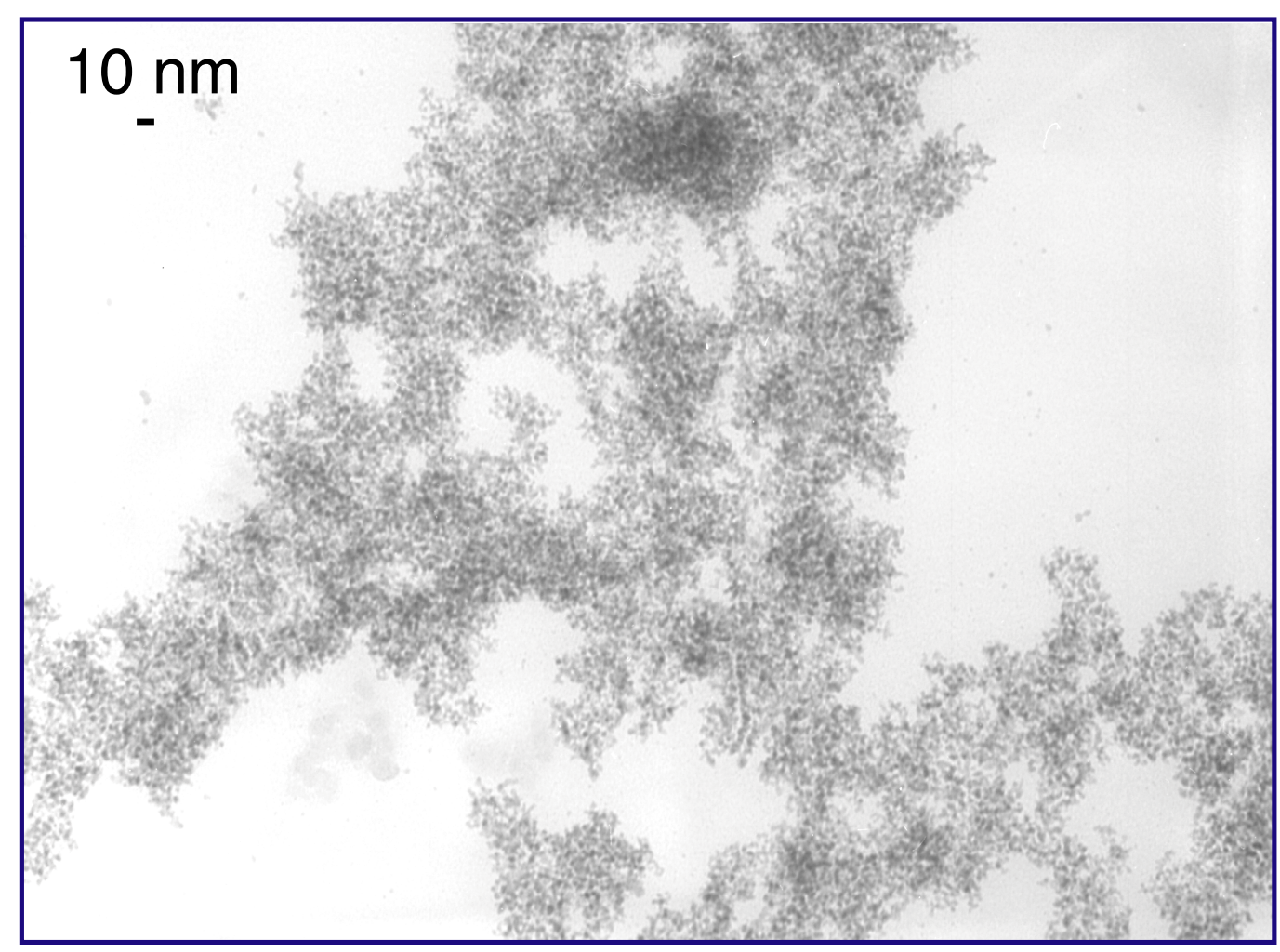

before catalysis

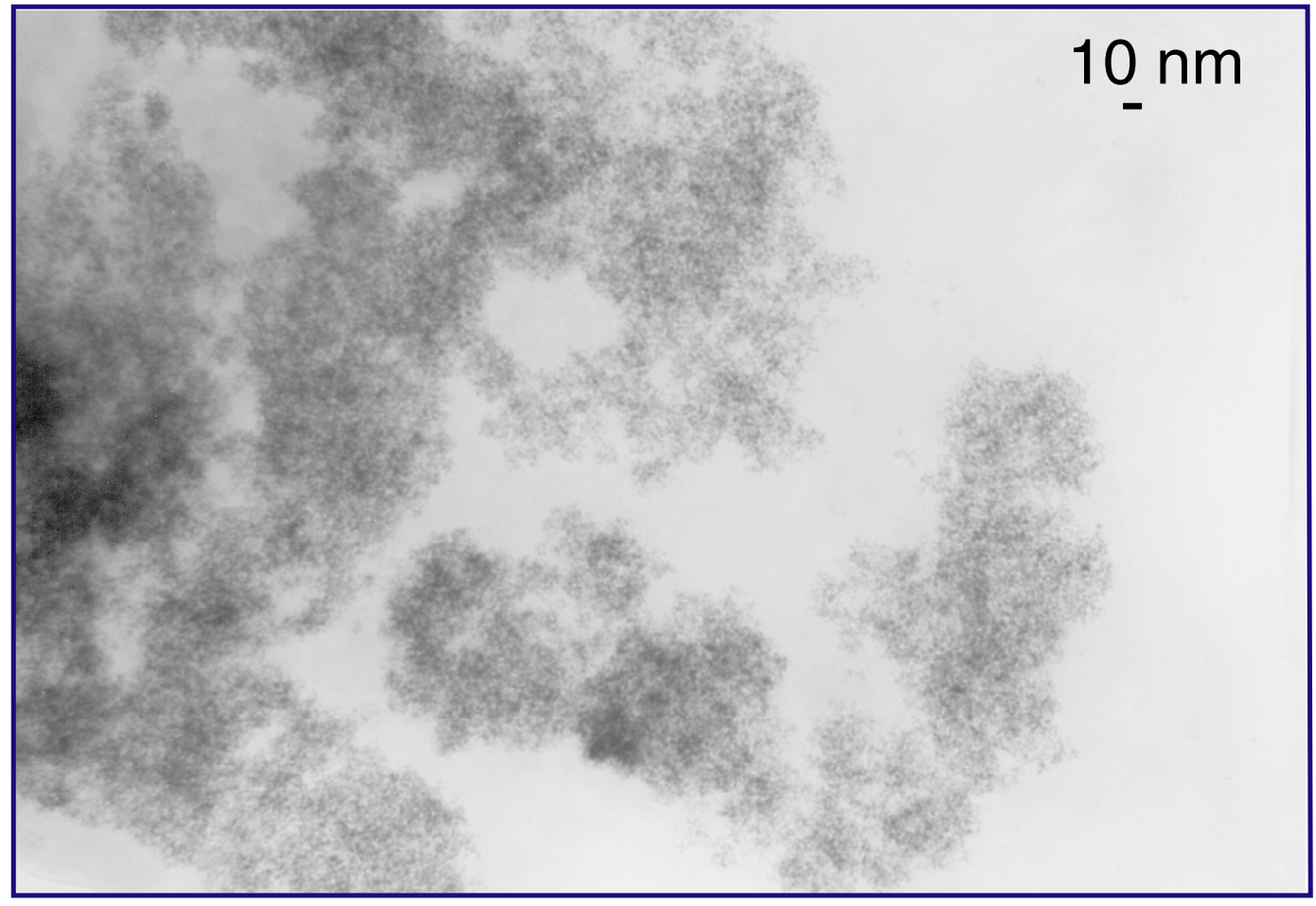

after catalysis (r.t., 7 days) 
Table S1: Elemental analysis of Coll. 1

\begin{tabular}{|c|c|}
\hline$\% \mathrm{C}$ & 14.68 \\
\hline$\% \mathrm{H}$ & 0.94 \\
\hline$\% \mathrm{Pd}$ & 81.72 \\
\hline$\% \mathrm{P}$ & 0.17 \\
\hline
\end{tabular}

Supposed formula for Coll.1 (determined from TEM and elemental analysis): $\mathrm{Pd}_{2869} \mathrm{~L}^{*}{ }_{11}(\mathrm{THF})_{32}$ (in the catalytic process, excess diphosphite is added). 


\section{B. EXPERIMENTAL PART OF CATALYTIC REACTIONS}

The results of the catalytic reactions involving Coll.1-3 and the molecular complex in the standard conditions (1/100) are reported in Table S1 herebelow. All reactions have been reproduced at least twice (four times for the colloidal catalysis, three times for the molecular 1/10,000).

\section{B.1 Procedure for allylic alkylation catalyzed by palladium nanoparticles}

$2.5 \mathrm{mg}$ of nanoparticle (Coll.1, Coll.2 or Coll.3) and $0.005 \mathrm{mmol}$ of ligand (for Coll.1: 5.0 mg of 1; for Coll.2: $1.9 \mathrm{mg}$ of 2; for Coll.3: $0.9 \mathrm{mg}$ of 3) were dissolved in $5 \mathrm{~cm}^{3}$ of $\mathrm{CH}_{2} \mathrm{Cl}_{2}$. $0.602 \mathrm{~g}$ (2.34 mmol) of rac-3-acetoxy-1,3-diphenyl-1-propene and dimethyl malonate $(0.930 \mathrm{~g}, 7.02 \mathrm{mmol})$, dissolved in $4 \mathrm{~cm}^{3}$ of $\mathrm{CH}_{2} \mathrm{Cl}_{2}$, were then added, followed by $\mathrm{N}, O$-bis(trimethylsilyl)acetamide (BSA) $(1.436 \mathrm{~g}, 7.02 \mathrm{mmol})$, and a catalytic amount of KOAc $(5.4 \mathrm{mg})$. The mixture was stirred at room temperature and samples $\left(0.5 \mathrm{~cm}^{3}\right.$ of reaction mixture) were taken off over ca. 7 days. Each sample was then diluted with diethyl ether $\left(20 \mathrm{~cm}^{3}\right)$, filtered over celite, and washed with a saturated aqueous solution of $\mathrm{NH}_{4} \mathrm{Cl}\left(3 \times 20 \mathrm{~cm}^{3}\right)$ and water $\left(2 \times 20 \mathrm{~cm}^{3}\right)$. The organic phase was dried over anhydrous $\mathrm{Na}_{2} \mathrm{SO}_{4}$, filtered off, and solvent removed under reduced pressure. The conversion was determined by ${ }^{1} \mathrm{H}$ NMR and the enantiomeric excesses were determined by HPLC on a Chiracel OD column, using hexane/isopropanol (99/1) as eluent, in a flow of $0.3 \mathrm{~cm}^{3} / \mathrm{min}$.

\section{B.2 Procedure for allylic alkylation catalyzed by palladium molecular systems}

$\mathrm{Pd} / \mathbf{I}=1 / 2000$

$1.8 \mathrm{mg}$ of $[\mathrm{Pd}(\mathrm{allyl}) \mathrm{Cl})]_{2}(0.0098 \mathrm{mmol})$ and 1.25 equivalents of $1(13.3 \mathrm{mg}, 0.0123$ mmol) were dissolved in $10 \mathrm{~cm}^{3}$ of $\mathrm{CH}_{2} \mathrm{Cl}_{2} .5 .04 \mathrm{~g}(20 \mathrm{mmol})$ of $\mathrm{rac}-\mathbf{I}(7.92 \mathrm{~g}, 60$ $\mathrm{mmol}$ ), dissolved in $10 \mathrm{~cm}^{3}$ of $\mathrm{CH}_{2} \mathrm{Cl}_{2}$, were then added, followed by BSA (12.22 $\mathrm{g}, 60$ mmol), and a catalytic amount of KOAc $(46 \mathrm{mg})$ dissolved in $40 \mathrm{~cm}^{3}$ of $\mathrm{CH}_{2} \mathrm{Cl}_{2}$. The mixture was stirred at room temperature and samples $\left(0.5 \mathrm{~cm}^{3}\right.$ of reaction mixture $)$ were taken off over ca. 8 hours. Each sample was then diluted with diethyl ether $\left(20 \mathrm{~cm}^{3}\right)$, filtered over celite, and washed with a saturated aqueous solution of $\mathrm{NH}_{4} \mathrm{Cl}\left(3 \times 20 \mathrm{~cm}^{3}\right)$ and water $\left(2 \times 20 \mathrm{~cm}^{3}\right)$. The organic phase was dried over anhydrous $\mathrm{Na}_{2} \mathrm{SO}_{4}$, filtered off, and solvent removed under reduced pressure. The conversion was determined by ${ }^{1} \mathrm{H}$ NMR and the enantiomeric excesses were determined by HPLC on a Chiracel OD column, using hexane/isopropanol (99/1) as eluent, in a flow of $0.3 \mathrm{~cm}^{3} / \mathrm{min}$.

$\mathrm{Pd} / \mathbf{I}=1 / 10000$

$0.18 \mathrm{mg}$ of $[\mathrm{Pd}(\mathrm{allyl}) \mathrm{Cl})]_{2}(0.000984 \mathrm{mmols})$ and 1.25 equivalents of 1 (1.33 $\mathrm{mg}$, $0.00123 \mathrm{mmol})$ were dissolved in $10 \mathrm{~cm}^{3}$ of $\mathrm{CH}_{2} \mathrm{Cl}_{2} .2 .56 \mathrm{~g}(10.1 \mathrm{mmol})$ of $\mathrm{rac}-\mathrm{I}$ and dimethyl malonate $\left(3.96 \mathrm{~g}, 30.4 \mathrm{mmol}\right.$ ), dissolved in $10 \mathrm{~cm}^{3}$ of $\mathrm{CH}_{2} \mathrm{Cl}_{2}$, were then added, followed by BSA $(6.11 \mathrm{~g}, 30.4 \mathrm{mmol})$, and a catalytic amount of KOAc (23 mg) dissolved in $20 \mathrm{~cm}^{3}$ of $\mathrm{CH}_{2} \mathrm{Cl}_{2}$. The mixture was stirred at room temperature and samples $\left(0.5 \mathrm{~cm}^{3}\right.$ of reaction mixture) were taken off over one week. Each sample was then diluted with diethyl ether $\left(20 \mathrm{~cm}^{3}\right)$, filtered over celite, and washed with a saturated aqueous solution of $\mathrm{NH}_{4} \mathrm{Cl}\left(3 \times 20 \mathrm{~cm}^{3}\right)$ and water $\left(2 \times 20 \mathrm{~cm}^{3}\right)$. The organic phase was dried over anhydrous $\mathrm{Na}_{2} \mathrm{SO}_{4}$, filtered off, and solvent removed under reduced pressure. Conversions and enantioselectivities were determined as described for the catalytic system $\mathrm{Pd} / \mathbf{I}=1 / 2000$. 
$\mathrm{Pd} / \mathbf{I}=1 / 100000$

$0.18 \mathrm{mg}$ of $[\mathrm{Pd}(\mathrm{allyl}) \mathrm{Cl})]_{2}(0.000984 \mathrm{mmols})$ and 1.25 equivalents of 1 (1.33 $\mathrm{mg}$, $0.00123 \mathrm{mmol}$ ) were dissolved in $10 \mathrm{~cm}^{3}$ of $\mathrm{CH}_{2} \mathrm{Cl}_{2} \cdot 1 \mathrm{~cm}^{3}$ of these solution was transferred into a schlenk and solvent was removed under reduced pressure. Then $2.56 \mathrm{~g}$ $(10.1 \mathrm{mmol})$ of $\mathrm{rac}$-I and dimethyl malonate $(3.96 \mathrm{~g}, 30.4 \mathrm{mmol})$, dissolved in $10 \mathrm{~cm}^{3}$ of $\mathrm{CH}_{2} \mathrm{Cl}_{2}$, were then added, followed by BSA $(6.11 \mathrm{~g}, 30.4 \mathrm{mmol})$, and a catalytic amount of KOAc $(23 \mathrm{mg})$ dissolved in $20 \mathrm{~cm}^{3}$ of $\mathrm{CH}_{2} \mathrm{Cl}_{2}$. The mixture was stirred at room temperature and samples $\left(0.5 \mathrm{~cm}^{3}\right.$ of reaction mixture $)$ were taken off over 2.5 days. The solution was then diluted with diethylether $\left(20 \mathrm{~cm}^{3}\right)$, filtered over celite, and washed with a saturated aqueous solution of $\mathrm{NH}_{4} \mathrm{Cl}\left(3 \times 20 \mathrm{~cm}^{3}\right)$ and water $\left(2 \times 20 \mathrm{~cm}^{3}\right)$. The organic phase was dried over anhydrous $\mathrm{Na}_{2} \mathrm{SO}_{4}$, filtered off, and solvent removed under reduced pressure. Conversions and enantioselectivities were determined as described for the catalytic system $\mathrm{Pd} / \mathbf{I}=1 / 2000$.

Table S1. Asymmetric allylic alkylation of rac-3-acetoxy-1,3-diphenyl-1-propene (racI) with dimethyl malonate catalyzed by Mol 1, Coll.1, Coll.2 and Coll.3 ${ }^{a}$

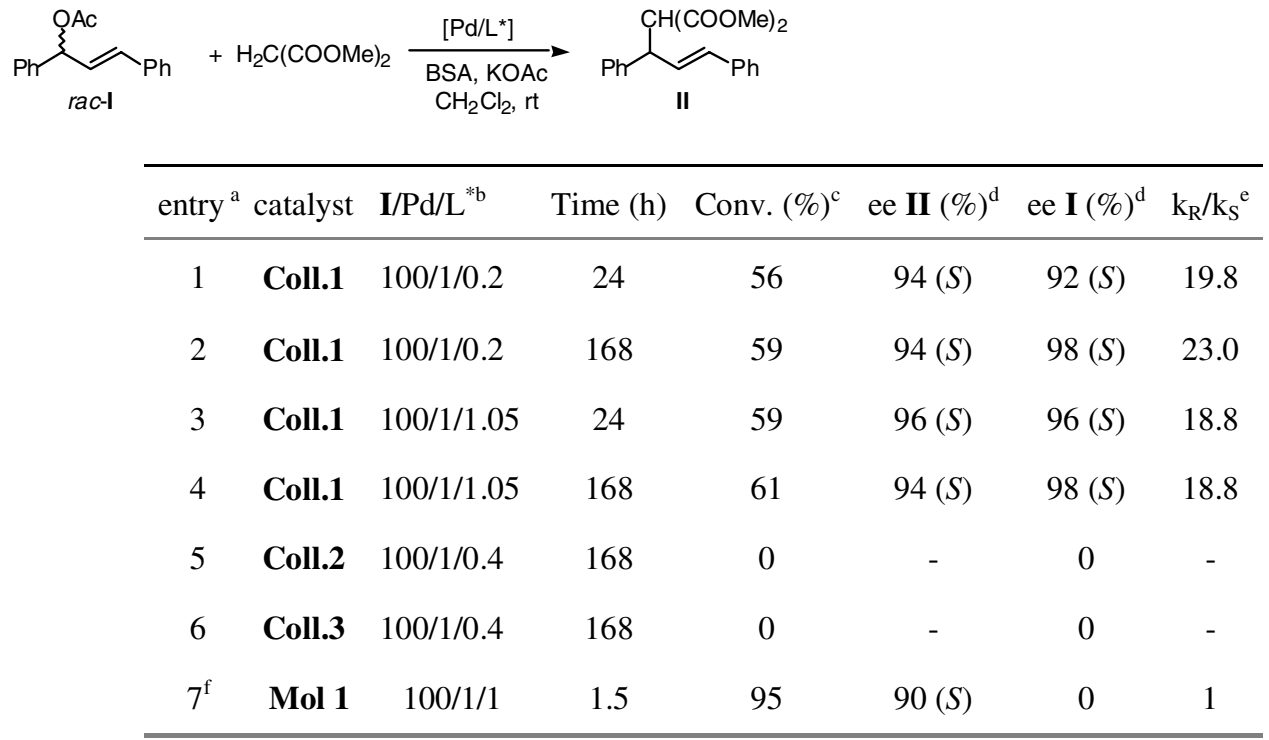

\footnotetext{
${ }^{a}$ Results from duplicated reactions. ${ }^{b}$ Molar ratio between I, Pd and excess ligand added in the catalysis. Determined by ${ }^{1} \mathrm{H}$ NMR. ${ }^{\mathrm{d}}$ Determined by HPLC on a Chiralcel-OD column. Absolute configurations of $\mathbf{I}$ (see Ref. 13c) and II (see Ref. 15) in parentheses. ${ }^{\mathrm{e}} \ln [(1-\mathrm{C} / 100)(1-\mathrm{ee} / 100)] / \ln [(1-\mathrm{C} / 100)(1+\mathrm{ee} / 100)](\mathrm{C}=$

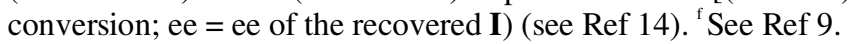




\section{COMPARATIVE STUDY OF ACTIVITY AND SELECTIVITY FOR THE Pd- CATALYSED ALLYLIC ALKYLATION, USING MOLECULAR AND COLLOIDAL SYSTEMS}

In order to achieve a true comparison between both colloidal and molecular catalytic systems, which display very different reaction rates, a series of experiments has been carried out with the homogenous molecular system, decreasing the catalyst concentration in the model allylic alkylation reaction of rac-3-acetoxy-1,3-diphenyl-1propene (rac-I) using dimethyl malonate as nucleophile, in Trost basic conditions (Equation S1). The course of the reaction has been monitored taking samples at different reaction times and analyzing each of them by ${ }^{1} \mathrm{H}$ NMR spectroscopy (to determine the conversion) and HPLC chromatography with chiral column (to determine the enantioselectivity of I and the substitution product, II).

Equation S1: allylic alkylation of $r a c$-3-acetoxy-1,3-diphenyl-1-propene ( $r a c$-I) with dimethyl malonate

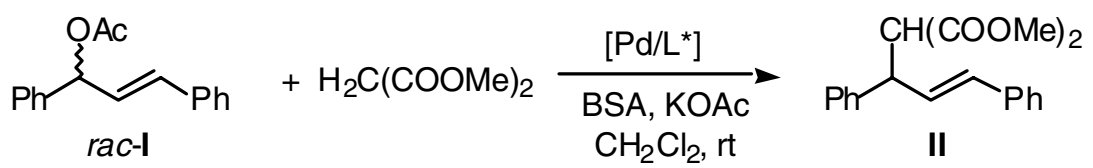

We have studied the following systems with different palladium/substrate ratios:
a) $\mathrm{Pd} / \mathbf{I}=1 / 500$
b) $\mathrm{Pd} / \mathbf{I}=1 / 2,000$
c) $\mathrm{Pd} / \mathbf{I}=1 / 10,000$

in addition to the standard homogeneous molecular system, $\mathrm{Pd} / \mathrm{I}=1 / 100(95 \%$ conversion of $\mathbf{I}$ after 1.5 hours)

In all cases, the molecular catalyst was generated under in situ conditions from $[\mathrm{Pd}(\text { allyl }) \mathrm{Cl}]_{2}$ and $\mathbf{1}$ (ratio $\left.\mathrm{Pd} / \mathbf{1}=1 / 1.25\right)$ as originally reported.

For systems using $\mathrm{Pd} / \mathbf{I}=1 / 500$ and $\mathrm{Pd} / \mathbf{I}=1 / 2,000$, total conversion of substrate was achieved after 7.5 and 18 hours, respectively, and no kinetic resolution of the substrate, rac-I, was observed. The e.e. for II was up to $98 \%(S)$.

For $\mathbf{P d} / \mathbf{I}=1 / 10,000$ system, $90 \%$ conversion of the substrate was obtained after 48 hours of reaction. Analytical data were further obtained from samples taken once per day, up to one week of reaction, the conversion reaching $95 \%$. The enantioselectivity of product II was found up to $98 \%(S)$ for all the analysed samples. Concerning the enantiomeric excess of $\mathbf{I}$, we observe a kinetic resolution, getting up to $46 \%(S)$ when the conversion was ca. $70 \%$, and $38 \%(S)$ for $55 \%$ conversion.

The colloidal system (Coll.1/1.05) has been also monitored up to one week, analogously to the molecular system $\mathrm{Pd} / \mathrm{I}=1 / 10000$. Comparing both systems, we observe two remarkable differences.

First, the molecular system leads to a total conversion of the substrate, while the colloidal one reaches ca. 60\%. In Figure S4, conversion of rac-I versus time (up to 24 h) is plotted for the colloidal and the three molecular systems. As clearly observed, for 
the first six hours of reaction, colloidal and $\mathbf{P d} / \mathbf{I}=1 / 10000$ molecular systems exhibit comparable activity.

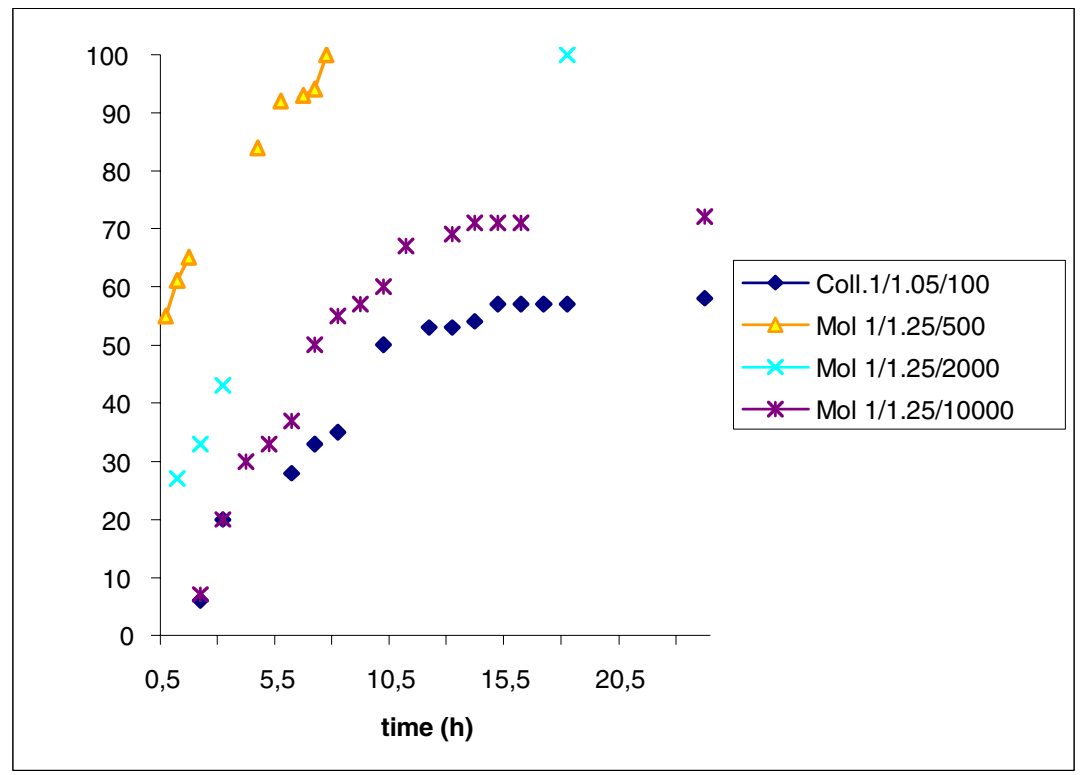

FIGURE S4: Plot of conversion of $r a c-I$ versus time for the colloidal and molecular $(\mathrm{Pd} / \mathbf{I}=1 / 500, \mathrm{Pd} / \mathbf{I}=1 / 2000$, and $\mathrm{Pd} / \mathbf{I}=1 / 10000)$ catalysts

In Figure S5, conversion of rac-I versus time (up to one week) is plotted for the colloidal and $\mathrm{Pd} / \mathbf{I}=1 / 10000$ molecular systems. For this time scale, the colloidal system is apparently "blocked" (see below "Reuse of colloidal catalytic system"), while the molecular catalyst works.

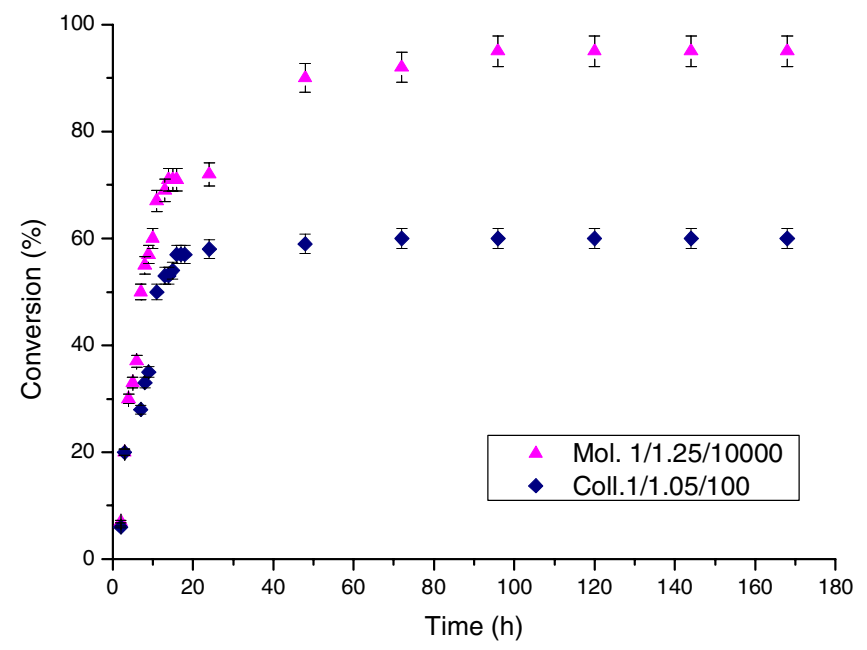

FIGURE S5: Plot of conversion of rac-I versus time for the colloidal and molecular $\mathrm{Pd} / \mathbf{I}=1 / 10000$ catalysts. 
The relative rate of both substrate isomers, $(R)$-I and $(S)$-I, is clearly different for both catalytic systems (see "Enriched substrate, I"). These data are collected in Figures S6 and S7.

In Figure S6 we observe that the enrichment of $(S)$-I with the reaction time, is higher for the colloidal than the molecular system. In Figure $\mathrm{S} 7$, the relative rate $(\mathrm{k} R / \mathrm{k} S)$ of both isomers, $(R)-\mathbf{I}$ and $(S)-\mathbf{I}$, is plotted versus time for both catalytic systems. For the colloidal catalyst this ratio is ca. 12 , while for the molecular catalyst it is ca. 2 . In addition, for the colloidal system, $\mathrm{k} R / \mathrm{k} S$ shows a dependence on time in contrast to the molecular system.

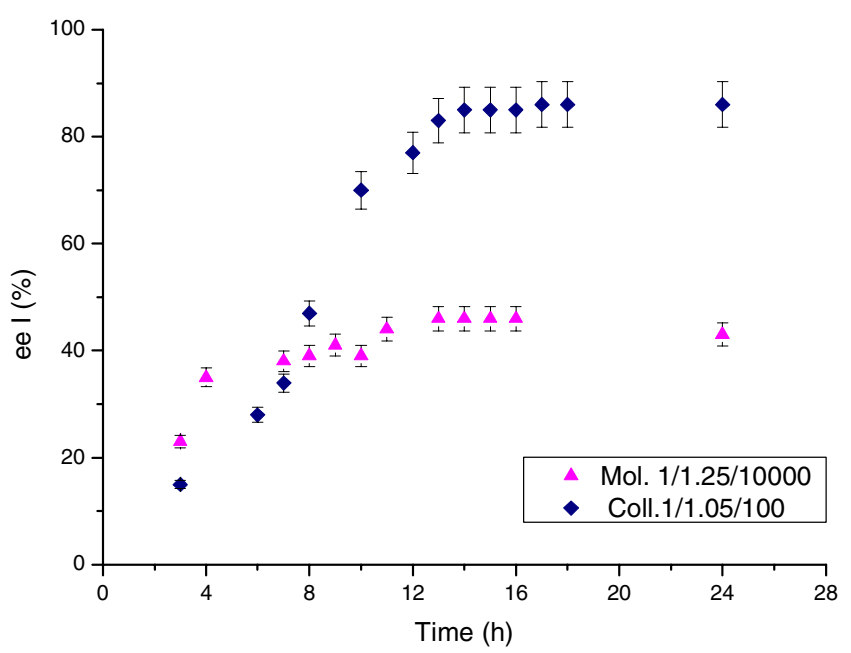

FIGURE S6: Plot of e.e. of I versus time for the colloidal and molecular Pd/I = 1/10000 catalysts.

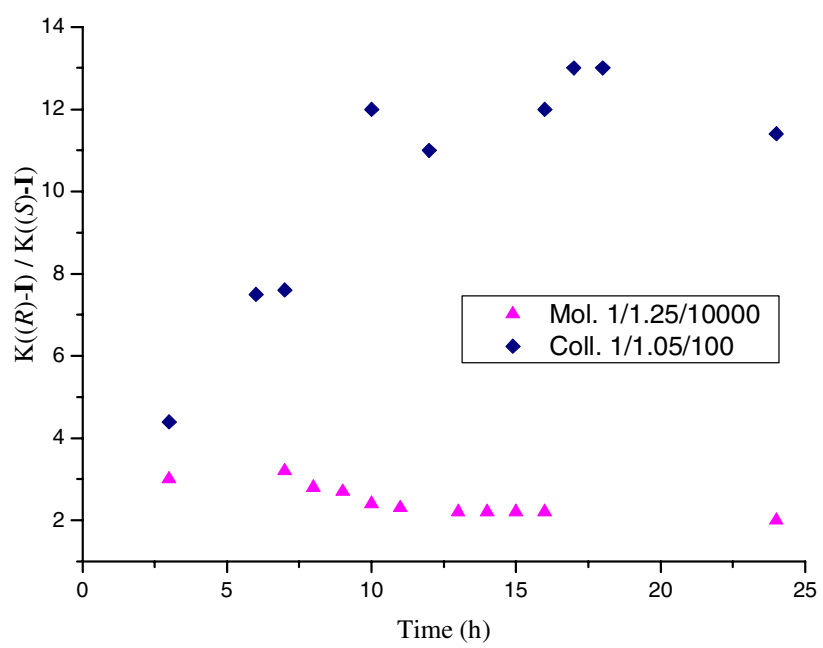

FIGURE S7: Plot of $\mathrm{k}((R)-\mathbf{I}) / \mathrm{k}((S)-\mathbf{I})$ versus time for the colloidal and molecular $\mathbf{P d} / \mathbf{I}=$ $1 / 10000$ catalysts.k $((R)-\mathrm{I}) / \mathrm{k}((S)-\mathrm{I})=\ln [(1-\mathrm{C} / 100)(1-\mathrm{ee} / 100)] / \ln [(1-\mathrm{C} / 100)(1+\mathrm{ee} / 100)]$, $\mathrm{C}=$ conversion of $\mathrm{rac}-\mathbf{I}$; ee $=$ enantiomeric excess of recovered $\mathbf{I}$ 


\section{REUSE OF COLLOIDAL CATALYTIC SYSTEM}

In order to verify if the colloidal catalytic system was still active after 24 hours, several additions of the substrate $r a c-\mathbf{I}$, were done on the reaction catalytic mixture. The data are collected in Table S2. Up to the third addition, no more than 53\% conversion was observed after each addition of substrate and no changes in activity and selectivity were visible. After the fourth addition, the catalyst lost activity.

Table S2. Activity and selectivity data for the allylic alkylation reaction (equation S1) using Coll.1 as catalyst. ${ }^{2}$

$\begin{array}{lllll}\text { Batch } & \text { time }(\mathrm{h}) & \text { conv. }(\%)^{\mathrm{b}} & \text { ee II }(\%)^{\mathrm{c}} & \text { ee I }(\%)^{\mathrm{c}} \\ 1 & 24 & 53 & 98(S) & 83(S) \\ 2 & +24 & 46 & 97(S) & 87(S) \\ 3 & +24 & 53 & 97(S) & 93(S)\end{array}$

${ }^{\text {a }}$ Catalytic reaction conditions: Coll.1 (ca. $\left.2.5 \mathrm{mg}\right)$ and $\mathbf{1}(0.005 \mathrm{mmol})$ in $5 \mathrm{~cm}^{3}$ of $\mathrm{CH}_{2} \mathrm{Cl}_{2}$. rac1,3-diphenyl-2-propenyl acetate $(602 \mathrm{mg}, 2.34 \mathrm{mmol})$, dissolved in $4 \mathrm{~cm}^{3}$ of $\mathrm{CH}_{2} \mathrm{Cl}_{2}$, was added, followed by dimethyl malonate $(930 \mathrm{mg}, 7.02 \mathrm{mmols})$, BSA (1.436 g, $7.02 \mathrm{mmols})$, and a catalytic amount of KOAc (5.4 mg). After each 24 hours, 2.34 mmols of rac-I was added.

${ }^{\mathrm{b}}$ Determined by ${ }^{1} \mathrm{H}$ NMR

'Determined by HPLC on a Chiralcel-OD column. Absolute configurations of I (Gilberston, S. R.; Lan, P. Org. Lett. 2001, 3, 2237) and II (Leutenegger, U.; Umbricht, G.; Fahrni, C.; Matt, P. V.; Pfaltz, A. Tetrahedron 1992, 48, 2143) in parentheses.

\section{E. ENRICHED SUBSTRATE, $(S)$-I}

Enriched I (more than $75 \%(S)$-I) was used as substrate for the allylic alkylation in the presence of both catalysts, namely the colloidal and the $\mathrm{Pd} / \mathbf{I}=1 / 10,000$ molecular one. As observed in Scheme S2, the colloidal system reacts slowly : only $8 \%$ of $(R)$-I is present in the substrate initially and this leads to a total conversion of ca.10\% $(\mathrm{kR} / \mathrm{kS}=$ 12). The molecular system reacts much faster : $11.5 \%$ of $(R)$-I is present initially and $67 \%$ of the mixture is converted in 24 hours. These results are in agreement with the calculated rate ratio between both enantiomers which is lower in the molecular system $(\mathrm{kR} / \mathrm{kS}=2$; see Figure $\mathrm{S} 7)$.

a)

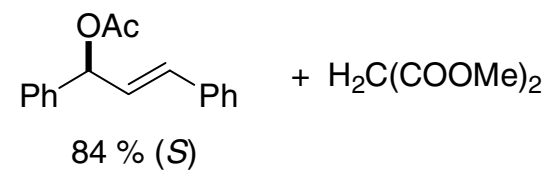

b)<smiles>CC(=O)OC(/C=C/c1ccccc1)c1ccccc1</smiles>

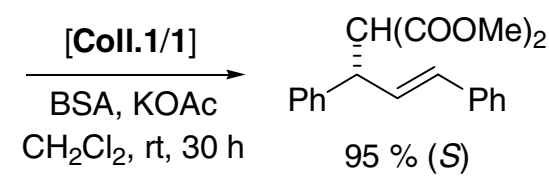

$10 \%$ conversion

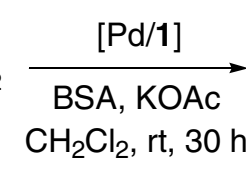

$67 \%$ conversion<smiles>COC(=O)C[C@H](/C=C/c1ccccc1)c1ccccc1</smiles> 
SCHEME S2: a) Colloidal catalyst. b) Molecular catalyst, $\mathrm{Pd} / \mathbf{1}=1 / 10,000$

\section{F. POISON TESTS: mercury and carbon disulfide}

In order to distinguish between a molecular and a colloidal catalysis, we also carried out experiments with the molecular system $(\mathrm{Pd} / \mathbf{1} / \mathbf{I}=1 / 1.25 / 50)$ and the colloidal one

(Coll.1/1/I $=1 / 1.05 / 100)$, by addition of mercury and carbon disulfide. These results are collected in Table S3.

For the molecular catalyst, the presence of mercury led to the same results than in its absence, and the presence of carbon disulfide led to a lower rate, with the same selectivity (entries 1-3). For the colloidal system, both $\mathrm{Hg}$ and $\mathrm{CS}_{2}$ were poisons for the organic process when they were added at the beginning of catalysis (entries 4 versus 57). But when they were added later ( $c a .4$ hours of the start of the reaction), only $\mathrm{CS}_{2}$ behaved as poison (entries 8 vs $9 ; 10$ vs 11 ).

Table S3. Activity and selectivity data for the allylic alkylation reaction (equation S1) using Coll.1 and Pd/50 molecular catalysts in the presence of poisons added after $3 \mathrm{~h}$ of reaction.

Catalyst Poison Pd/1/poison time $\quad$ Conv. $^{\text {a }} \quad$ ee $\mathbf{I I}^{\mathrm{b}} \quad$ ee $\mathbf{I}^{\mathrm{b}}$

(h) $\quad(\%) \quad(\%) \quad(\%)$

Molecular ${ }^{\mathrm{c}}$

$\begin{array}{llllll} & 1 / 1.25 / 0 & 1.5 & 95 & 87(S) & - \\ \mathrm{Hg} & 1 / 1.25 / 100 & 1.5 & 97 & 97(S) & \text { nd } \\ \mathrm{CS}_{2} & 1 / 1.25 / 4 & 5 & 79 & 98(S) & 0\end{array}$

Colloidal $^{\mathrm{d}}$

\begin{tabular}{|c|c|c|c|c|c|}
\hline - & $1 / 0.2 / 0$ & 24 & 45 & $97(S)$ & $84(R)$ \\
\hline $\mathrm{Hg}$ & $1 / 0.2 / 100$ & 24 & 0 & - & 0 \\
\hline $\mathrm{CS}_{2}$ & $0.3 / 0.2 / 0.3$ & 20 & 0 & - & 0 \\
\hline $\mathrm{CS}_{2}$ & 0.3/0.2/0.6 & 20 & 0 & - & 0 \\
\hline & $1 / 0.2 / 0$ & 3.75 & 6 & nd & $4(R)$ \\
\hline then & $1 / 0.2 / 100$ & 24 & 33 & $98(S)$ & $84(R)$ \\
\hline & $1 / 0.2 / 0$ & 3.75 & 9 & nd & $10(R)$ \\
\hline hen & $0.3 / 0.2 / 0.3$ & 24 & 11 & $98(S)$ & $10(R)$ \\
\hline
\end{tabular}

${ }^{a}$ Determined by ${ }^{1} \mathrm{H}$ NMR

${ }^{b}$ Determined by HPLC on a Chiralcel-OD column. Absolute configurations of I (Gilberston, S. R.; Lan, P. Org. Lett. 2001, 3, 2237) and II (Leutenegger, U.; Umbricht, G.; Fahrni, C.; Matt, P. V.; Pfaltz, A. Tetrahedron 1992, 48, 2143) in parentheses.

${ }^{c}$ Catalytic reaction conditions: Molecular catalyst was generated from $\left[\mathrm{Pd}\left(\mathrm{C}_{3} \mathrm{H}_{5}\right) \mathrm{Cl}\right]_{2}(0.02 \mathrm{mmols})$ and $\mathbf{1}$ (0.05 mmols) in $2 \mathrm{~cm}^{3}$ of $\mathrm{CH}_{2} \mathrm{Cl}_{2}$, stirring for 30 minutes at rt. rac-1,3-diphenyl-2-propenyl acetate (252 $\mathrm{mg}, 1 \mathrm{mmol}$ ), dissolved in $2 \mathrm{~cm}^{3}$ of $\mathrm{CH}_{2} \mathrm{Cl}_{2}$, was added, followed by dimethyl malonate (396 $\mathrm{mg}, 3$ mmols), BSA (610 mg, 3 mmols), and a catalytic amount of KOAc. Then the poison agent was added (Hg or $\mathrm{CS}_{2}$ ).

${ }^{\mathrm{d}}$ Catalytic reaction conditions: Coll.1 (ca. $2.5 \mathrm{mg}$ ) and $1(0.005 \mathrm{mmol})$ in $5 \mathrm{~cm}^{3}$ of $\mathrm{CH}_{2} \mathrm{Cl}_{2}$. rac-1,3diphenyl-2-propenyl acetate (602 mg, $2.34 \mathrm{mmol}$ ), dissolved in $4 \mathrm{~cm}^{3}$ of $\mathrm{CH}_{2} \mathrm{Cl}_{2}$, was added, followed by dimethyl malonate (930 mg, $7.02 \mathrm{mmols})$, BSA (1.436 g, $7.02 \mathrm{mmols})$, and a catalytic amount of KOAc $(5.4 \mathrm{mg})$. Then the poison agent was added $\left(\mathrm{Hg}\right.$ or $\left.\mathrm{CS}_{2}\right)$. 